\title{
Exaltação aos Inventores
}

Tiro minha cartola, reverente

Pro galhardo bahiano assaz valente

Dos batutas exalto o som e o dom

De dongaroto e do menino bom

Babo pela magnífica, divina

E notável pequena linda flor

Devoto de Gonzaga e do divino

Eu rendo graças ao nosso sinhô

Bebo na fonte de cascata e cascatinha

De ribeiro e riachão

Colho do fruto benedito de oliveiras

De pereira, de moreiras

De carvalho e jamelão

Devoro jararaca e ratinho

Mordo a carmen de peixoto

Lobos e martins

Degluto batatinha e gordurinha

Como clementina

Chupo amorim

Tomo cachaça e fumo charutinho

Baixa um caboclinho

Danço ao wil-som do pandeiro

Do bandolim, viola e cavaquinho

Baixa um rouxinol

E por fim um seresteiro

Então qual um joão-de-barro, um ás

De um bando de tangarás

Ou como quem também se sabe um sabiá

Canto lalá, lalá, lalá, lalá! 
Cantando o "nobre lobo" Ataulfo

"O poderoso" Ciro, "o valoroso" Ary

Mirando la Miranda, a "admirável"

E ao canto da "cigarra" Aracy

Subi lau-rindo a voz-do-morro num capiba

Do "montanhês" Orestes celestino

Roland-o morro abaixo, de-cay-mmi

No "vale d'ouro" Dorival marino

\section{E como num filme:}

$\mathrm{O}$ ar da aurora hum(ber)tei-cheira a (noel)rosa

Orl-ando (e silvo) por um la-marçal barroso

Por vales e por lagos encantados

Por mários nunca dantas navegados

E escuto o velho lupus ulular

Ao luar tão cândido

Seu cântico mansueto pelo ar

Junto-me kéti-nho ao bando

Dos namorados da lua

E tomo um banho de lua

De luz e de inspiração

A estrela dalva sobre o ab-ismael

Nos en-candeia no blecaute da amplidão

Entre os anjos do inferno e os diabos do céu

Vivo dos prazeres

E dolores da paixão

Re-cito Lamartine pra de-déo

Enfim sou um Catulo da canção
Descendente de príncipe e princesa

De reis e rainhas

De preferidas e personalíssimas

De vermelho brancura e zé pretinho

De alvinho alvaiade e índio

Da tribo de bororó

Do clã dos cariocas da baiana

Cria de crioulos

Filho de Pernambuco e Bahia

Parente de americano

Sob a guarda de custódio

E as ordens do comandante

Do exército de sargento

E da armada de almirante

Canto aqui meus inventores

Que eu elegi pra meus antecessores

À deles eu juntei a minha voz

E đeles fiz meus pais e meus avós

- Uma hora acaba

Tudo que começa

— Entāo vamos nelson

Que é bom à beça 
[Lista das referências]

Tiro minha cartola (1), reverente

Pro galhardo (2) bahiano (3) assaz valente (4)

Dos batutas (5) exalto o som e o dom

De um dongaroto (6) e do menino bom (7)

Babo (8) pela magnifica divina (9)

E notável pequena (10) linda flor (11)

Devoto de Gonzaga (12) e do divino (13)

Eu rendo graças ao nosso Sinhô (14)

Bebo na fonte de cascata (15) e cascatinha (16)

De ribeiro (17) e riachı̃o (18)

Colho do fruto benedito (19) de oliveiras (20)

De pereira (21), de moreiras (22)

De carvalho (23) e jamelão (24)

Devoro jararaca (25) e ratinho (26)

Mordo a carmen (27) de peixoto (28)

Lobos (29) e martins (30)

Degluto batatinha (31) e gordurinhn (32)

Como clementina (33)

Chupo amorim (34)

Tomo cachaça (35) e fumo charutinho (36)

Baixa um caboclinho (37)

Danço no wil-som (38) do pandeiro (39)

Do bandolim (40), viola (41) e cavaquinho (42)

Baixa un rouxinol (43)

E por fim um seresteiro (44)

Entĩo qual um joão-de-barro (45), um as (46)

De um bando de tangarás (47)

Ou como quem tanlbém se sabe um sabiá

Canto lalí, lalí, lalí, lalá! (48)

Cantando o "nobre lobo" (49) Atnulfo

"O poderoso" (50) Ciro, "o valoroso" (51) Ary

Mirando la Miranda a "admirivel" (52)
E ao canto da "cigarra" (53) A racy"

Subi lau-rindo (54) a voz-do-morro (55) num capiba (56)

Do "montanhês" (57) Orestes celestino (58)

Roland-o (59) morro abaixo de-cay-mmi (60)

No "vale d"ouro" (61) Dorival marino (62)

E como num filme (115):

O ar da aurora (63) hum(ber)tei-cheira (64) a (noel)rosa (65)

Orl-ando (e silvo) (66) por um la-marçal (67) barroso (68)

Por vales (69) e por lagos (70) encantados

Por mários (71) munca dantas (72) navegados

E escuto o velho lupus (73) ulular

Ao luar tão cândido (74)

Seu cántico mansuero (75) pelo ar

Junto-me kéti-nho (76) ao bando

Dos namorados da lua (77) (78)

E tomo un banho de lua (79)

De lız e de inspiração

A estrela dalva (80) sobre o ab-ismael (81)

Nos en-candeia (82) no blecaute (83) da amplidão

Entre os anjos do inferno (84) e os diabos do céu (85)

Vivo dos prazeres (86)

E dolores (87) da paixão (88)

Re-cito Lamartine (89) pra de-déo (90)

Encarno um Catulo (91) da canção

Descendente de príncipe (92) e princesa (93)

De reis (94) e rainhas (95)

De preferidas (96) e personalissimas (97)

De vermelho (98) brancura (99) e zé pretinho (100)

De alvinho (101) alvaiade (102) e indio (103)

Da tribo de bororó (104)

Do clã dos cariocas (105) da baiana (106)

Cria de crioulos (107)

Filho de Pernambuco (108) e Bahia (109)

Parente de americano (110) 
Sob a guarda de custódio (111)

$E$ as ordens do comandante (112)

Do exército de sargento (113)

E da armada de almirante (114)

Canto aqui meus inventores

Que eu elegi pra meus antecessores

$A$ deles eu juntei a minha voz

$E$ deles fiz meus pais e meus avós

- Uma hora acaba

Tudo que começa

- Entâo vamos nelson (116)

Que é bom à beça

\section{Cartola}

2. Carlos Galhardo

3. Bahiano (que lançou "Pelo Telefone")

4. Assis Valente

5. Os Oito Batutas

6. Donga (donga quer dizer menino) e Garoto

7. Pixinguinha (também chamado de Pizindim, que quer dizer "menino bom")
8. Lamartine Babo
9. Elizete Cardoso (a magnifica, a divina)
10. Carmen Miranda
11. Aracy Cortes
12. Luiz Gonzaga (Gonzaga: são Gonzaga)
13. Cartola
14. Sinhô
15. Jota Cascata
16. Cascatinha
17. Alberto Ribeiro
18. Riachão

19. Benedito Lacerda

20. Aluísio, Angelino, Dalva, Mylton, Paulo Beijamin (Paulo da Portela) e Silas de Oliveira

21. Geraldo Pereira

22. Adelino e Bucy Moreira, Moreira da Silva

23. Joubert de Carvalho

24. Jamelāo

25. Jararaca

26. Ratinho

27. Carmen Miranda

28. Luiz Peixoto

29. Ary, Fernando e Haroldo Lobo

3o. Herivelto e Roberto Martins

31. Batatinha

32. Gordurinha

33. Clementina de Jesus (clementina é fruta)

34. Jair Amorim (amorim é fruta)

35. Carlos Cachaça

36. Adoniran Barbosa

37. Silvio Caldas

38. Wilson Batista

39. Jackson do Pandeiro

40. Jacó do Bandolim

41. Chico Viola e Mano Décio da Viola

42. Nelson Cavaquinho

43. Dalva de Oliveira

44. Silvio Caldas

45. Joāo de Barro (Braguinha)

46. Quatro Ases e um Coringa

47. Bando de Tangarás (do qual faziam parte João de Barro, Noel Rosa, Almirante e Alvinho)

48. Lamartine Babo

49. Ataulfo (Alves) significa "nobre lobo"

50. Ciro (Monteiro) significa "o poderoso"

51. Ary (Barroso) significa "o valoroso" 
52. Miranda (Carmen) significa "admirável" 53. Aracy (de Almeida) significa "cigarra" 54. Laurindo de Almeida 55. A Voz do Morro (conjunto) 56. Capiba (capiba é um jumento) 57. Orestes (Barbosa) significa "montanhês" 58. Vicente Celestino

59. Nuno Roland

6o. Dorival Caymmi

61. Dorival (Caymmi) significa "vale d'ouro"

62. Marino Pinto

63. Aurora Miranda

64. Humberto Teixeira

65. Noel Rosa

66. Orlando Silva

67. Armando Marçal

68. Ary e Inezita Barroso

69. João do Vale

70. Mário Lago

71. Mário Lago, Mário Reis

72. Zé Dantas

73. Lupicinio Rodrigues, o velho Lupe (lupe, lobo - lupus)

74. Cândido das Neves

75. Monsueto Menezes

76. Zé Kéti

77. Namorados da Lua

78. Bando da Lua

79. Luiz Gonzaga

80. Dalva de Oliveira

81. Ismael Silva

82. Candeia

83. Blecaute

84. Anjos do Inferno

85. Diabos do Céu

86. Heitor dos Prazeres

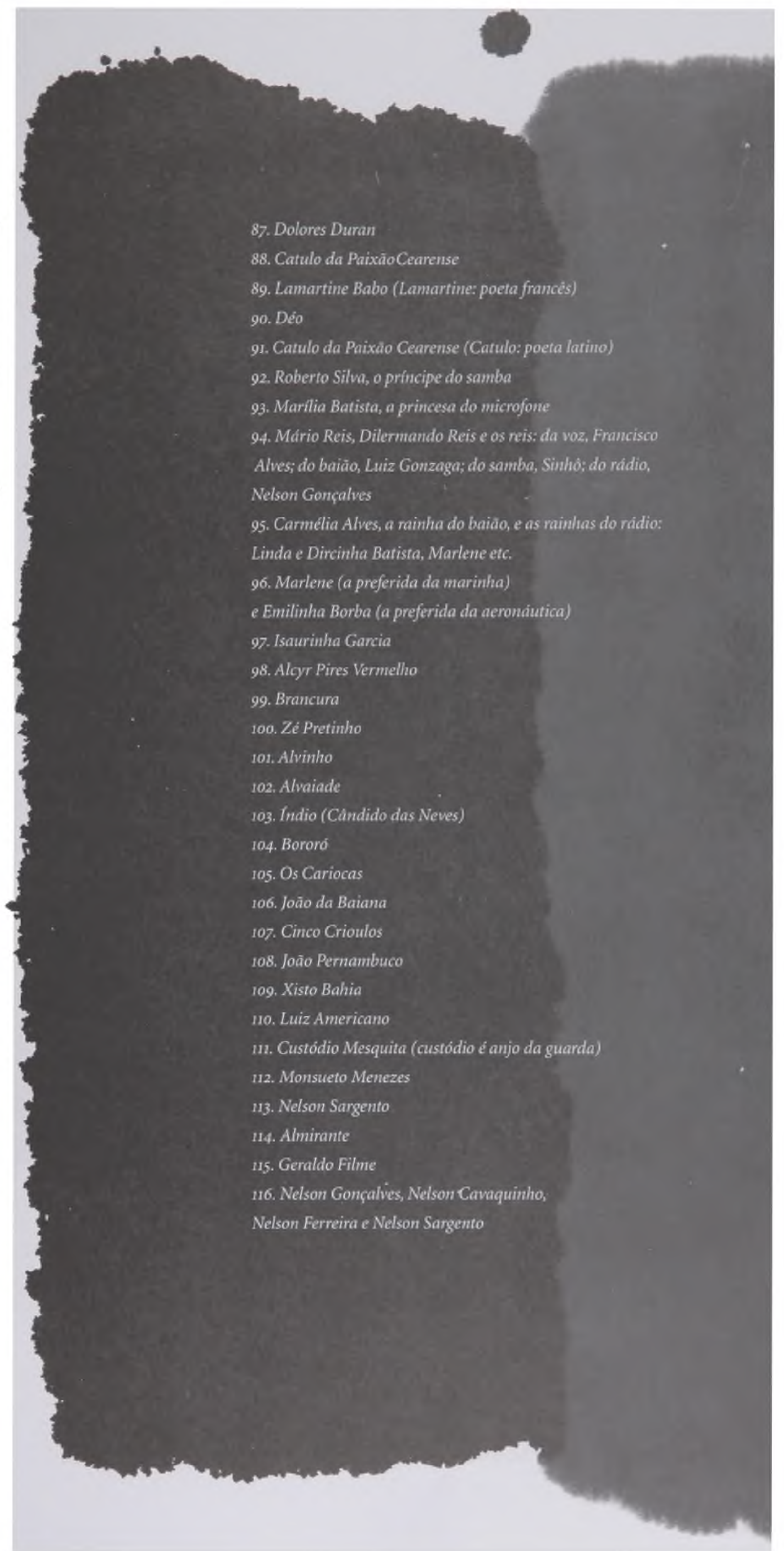

